\title{
Is it Possible to Suffer from Simultaneous Contralateral Knee and Elbow Dislocation after Falling down? A Case Report
}

\author{
D Mustafa Enes Demirel, ${ }^{1}$ (1) Hassan Salad² \\ 'Deparment of Emergency Medicine, Anamur State Hospital, Mersin, Turkey \\ ²Department of Orthopedics and Traumatology, Somalia - Turkey Training and Research Hospital \\ Mogadishu, Somalia
}

\section{ABSTRACT}

Isolated knee and elbow dislocations due to falls are frequently observed. However, dislocation of the knees and elbows accompanied by that of other joints are less common. Ipsilateral dislocations have been reported in the literature, although less frequently. When properly evaluated and diagnosed, most fallen and sportrelated dislocation can be reduced and initially managed at the game and reducing weight to prevent excessive weight gain and obesity, which can be a risk factor of fallen related dislocations and fractures, particularly female. There is little information available regarding isolated knee-elbow dislocation in normal population and athletes, slips and falls that result in elbow-knee dislocation injuries occur when the bones in joints are forced out of alignment. Complications that result from dislocations include accumulation of scar tissue that restricts the ability to move the joint and increased tendency for repeated dislocations. In addition to the surgical treatment, medical treatment, physical therapy and weight loss may help to heal dislocations. Here, we report a case of contralateral knee-elbow dislocation for the first time in the literature.

Please cite this article as: Demirel ME, Salad H. Is it Possible to Suffer from Simultaneous Contralateral Knee and Elbow Dislocation after Falling down? A Case Report. Anatol J Family Med 2020;3(2):188-190.

Address for correspondence: Dr. Mustafa Enes Demirel. Deparment of Emergency Medicine, Anamur State Hospital, Mersin, Turkey

Phone: +905053910903

E-mail: mnsdmrl@hotmail.com

Received Date: 30.09 .2019

Accepted Date: 08.03.2020

Published online: 21.08 .2020

(C) Copyright 2020 by Anatolian Journal of Family Medicine -

Available online at Www.anatoljfm.org

OPEN ACCESS

Keywords: Elbow joint, injury, joint dislocation, knee dislocation

\section{INTRODUCTION}

Trauma is one of the leading causes of death in adults and children. ${ }^{[1]}$ Therefore, the approach to trauma becomes more important in areas with the younger population. ${ }^{[2]}$ Isolated dislocations are often one-sided and frequently observed. Shoulder dislocations are the most frequently encountered, followed by elbow dislocations. ${ }^{[3]}$

Although elbow and shoulder dislocations are common, knee dislocations consist of $<0.2 \%$ of all orthopaedic traumas. ${ }^{[4]}$ However, the real prevalence of spontaneous reduction is unclear because half the cases of knee dislocations are accompanied by ligamental injuries. ${ }^{[5,6]}$

Although simultaneous dislocations are rare, knee and shoulder dislocations and hip and knee dislocations have been reported in the literature. ${ }^{[7,8]}$ Simultaneous knee and elbow dislocations are very rare. Here, we report a case of contralateral elbow and knee dislocation for the first time in the literature.

\section{CASE REPORT}

A 26-year-old female patient was brought to our emergency department by her relatives after a fall. Physical examination revealed a Glasgow coma scale of 15 . The patient was conscious, 
oriented and cooperative. The body mass index of the patient, who was overweight, was $36.7 \mathrm{~kg} / \mathrm{m}^{2}$. Both hemithoraces joined the respiration equally, and respiratory sounds were normal. The abdominal examination did not reveal any defense or rebound. The examination of the extremities showed a shape deformity of the left elbow and right knee. During the anamnesis, the patient, who had no history of chronic disease, had ecchymosis on her left elbow. Her pulse was steady on both hands. No coldness or paleness was observed at the distal end of the dislocations. Neurological and other system examinations revealed normal findings. Her vital symptoms were as follows: arterial blood pressure: 143/79 mmHg, $\mathrm{O}_{2}$ saturation level: $97 \%$ and pulse rate: $102 / \mathrm{min}$. Complete blood count parameters were white blood count 9800 cells $/ \mathrm{mm}^{3}(4-10 \times 1000$ cells $\left./ \mathrm{mm}^{3}\right)$, hemoglobin $9.1 \mathrm{~g} / \mathrm{dL}(12-16 \mathrm{~g} / \mathrm{dL})$, thrombocyte count 98700 cells $/ \mathrm{mm}^{3}\left(100-430 \times 1000\right.$ cells $\left./ \mathrm{mm}^{3}\right)$. Coagulation parameters were as follows: bleeding time 17 sec (10-16 sec), international normalised ratio 1.3 IU. Posterior dislocation of the left elbow and anteromedial dislocation of the right knee were detected in the radiographic images (Figure 1 and Figure 2).

The patient was administered tramadol as an analgesic and elbow reduction was performed. The patient requested an orthopaedic consultation. As the patient refused to undergo reduction under general anaesthesia, midazolam ( $4 \mathrm{mg}$ )

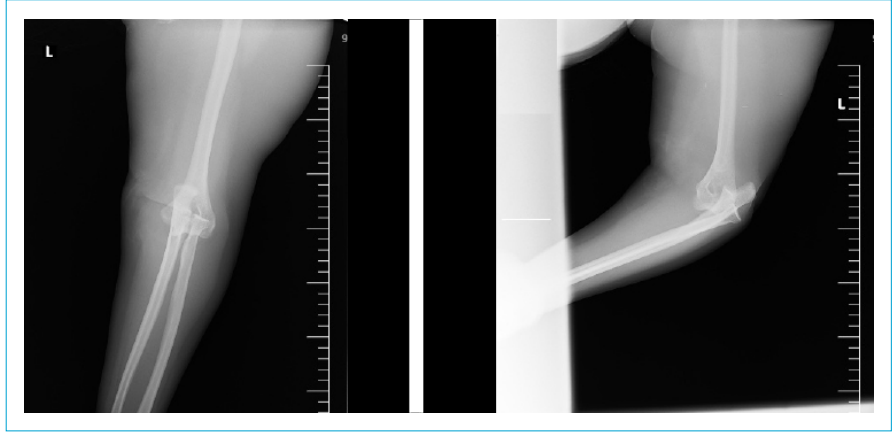

Figure 1. Dislocation of the left elbow on radiography.
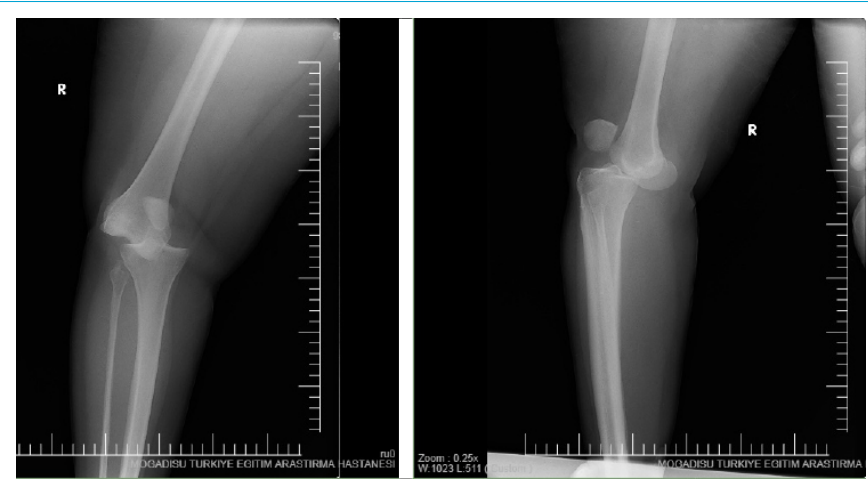

Figure 2. Dislocation of the right knee on radiography. was prescribed, and knee joint reposition was performed under sedation with the orthopaedic consultant physician. No neurovascular pathology was detected on repeated examination. Once reduction was confirmed by imaging, the elbow joint of the patient was put into a splint and the knee was put into a cast splint at $15-20^{\circ}$ flexion (Figure 3 and Figure 4). Joint movements were evaluated to be normal during the 1-month follow-up.

\section{DISCUSSION}

Contralateral knee and elbow dislocations are rarely seen together. In this report, we present the first such case in the literature. Knee dislocation may be observed after a highenergy event, such as traffic accident or after a low-energy event, such as falls. Knee dislocation is classified into anterior, posterior, medial, lateral and rotational, according to the relationship of the femur with the tibia. Rotational dislocations are of four subgroups: anteromedial, anterolateral, posteromedial and posterolateral. ${ }^{[9]}$ Studies on knee dislocations showed that anterior dislocation is the most common type due to hyperextension injuries. The second most common type is posterior dislocation, especially due to high-speed trauma. ${ }^{[10,11]}$ Nerve injury is seen in $16 \%-40 \%$ of the cases. Peroneal nerve damage can be observed in almost all knee dislocations. ${ }^{[10]}$ Early diagnosis and treatment are important since traumatic knee dislocations are an orthopaedic emergency. ${ }^{[11]}$ Treatment may include cast

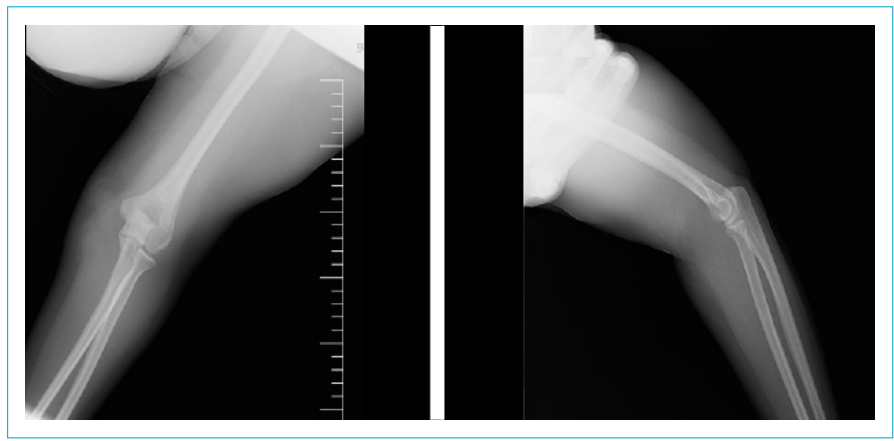

Figure 3. Elbow joint after reduction on radiography.
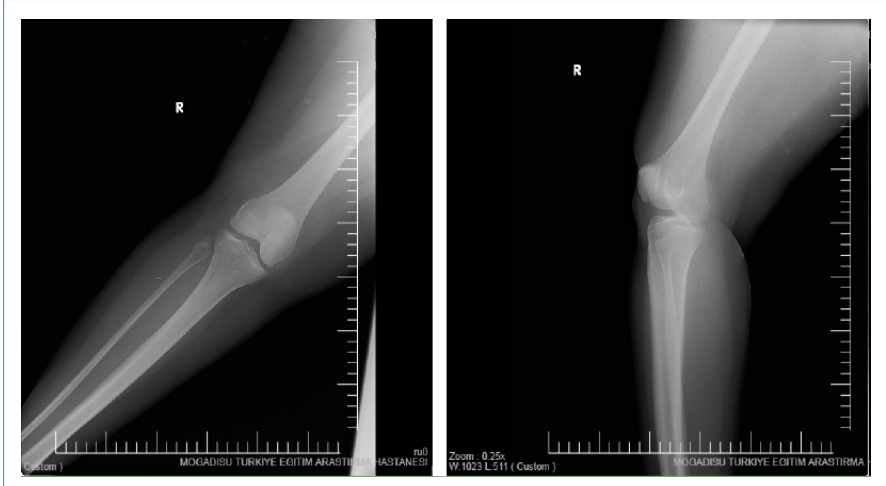

Figure 4. Knee joint after reduction on radiography. 
conservative treatment or surgical intervention. ${ }^{[12]}$ When the diagnosis is confirmed, dislocation should be reduced as soon as possible with sedation. Generally, the reduction can be performed with longitudinal traction. If reduction cannot be performed at admission, it should be performed under general anaesthesia. ${ }^{[12]}$ In our patient, anteromedial dislocation, which is very rare, was observed with no neurovascular pathologies. Since the patient refused the surgical reduction, cast conservative treatment was conducted under sedation at the emergency service.

Elbow dislocations are classified as anterior, posterior, lateral and divergent according to the injury direction of simple dislocations. Complex dislocations are classified as anterior and posterior. ${ }^{[13]}$ Although collateral ligaments are usually torn in simple elbow dislocations, surgical treatment is rarely necessary. Treatment is usually closed reduction. ${ }^{[14]}$

The reduction should preferably be performed under anaesthesia. ${ }^{[14]}$ As our patient who had posterior dislocation refused anaesthesia, the procedure was performed only with sedation. Post-traumatic joint stiffness can be counted among complications that may be observed after the treatment of elbow dislocations. ${ }^{[14]}$ More than three weeks of immobilisation is not recommended for simple dislocations. ${ }^{[15]}$ Pain and limitations were not observed in the joint movements of the patient during the 2-month follow-up.

As seen in this case, we should be more careful with overweight patients who come to the emergency room after falls not to miss the dislocations in other extremities due to skin folds while focusing on the dislocations of one side.

\section{Disclosures}

Informed Consent: Written informed consent was obtained from the patient for the publication of the case report.

Peer-review: Externally peer-reviewed.

Authorship contributions: Concept - M.E.D., H.S.; Design M.E.D., H.S.; Supervision - M.E.D., H.S.; Materials - M.E.D., H.S.; Data collection \&/or processing - M.E.D., H.S.; Analysis and/or interpretation - M.E.D.; Literature search - M.E.D., H.S.; Writing M.E.D., H.S.; Critical Review - M.E.D.

\section{REFERENCES}

1. Fingerhut LA, Warner M. Health, United States, 1996-97 and Injury Chartbook. Available at: https://www.cdc.gov/nchs/ data/hus/hus96_97.pdf. Accessed Mar 31, 2020.

2. Şahin H, Uzkeser M, Aköz A, Emet M, Aslan Ş, Gökcan Çakır Z. Traumatic Knee Dislocation with Acute Artery Injury. Konuralp Tıp Dergisi 2014;6:59-62.

3. Josefsson PO, Nilsson BE. Incidence of elbow dislocation. Acta Orthop Scand 1986;57:537-8.

4. Seroyer ST, Musahl V, Harner CD. Management of the acute knee dislocation: the Pittsburgh experience. Injury 2008;39:710-8.

5. Hegyes MS, Richardson MW, Miller MD. Knee dislocation. Complications of nonoperative and operative management. Clin Sports Med 2000;19:519-43.

6. Sisto DJ, Warren RF. Complete knee dislocation. A follow-up study of operative treatment. Clin Orthop Relat Res 1985;94101.

7. Imerci A, Kumbaraci M, İncesu M, Savran A, Karapinar L. Ipsilateral simultaneous shoulder and elbow dislocation a case report. Tr J Emerg Med 2011;11:72-5.

8. DuBois B, Montgomery WH Jr, Dunbar RP, Chapman J. Simultaneous ipsilateral posterior knee and hip dislocations: case report, including a technique for closed reduction of the hip. $J$ Orthop Trauma 2006;20:216-9.

9. Shelbourne KD, Klootwyk TE. Low-velocity knee dislocation with sports injuries. Treatment principles. Clin Sports Med 2000;19:443-56.

10. Brautigan B, Johnson DL. The epidemiology of knee dislocations. Clin Sports Med 2000;19:387-97.

11. Smith MB, Bancroft LW. Radiologic case study: knee dislocation and ligamentous reconstruction. Orthopedics 2008;31.

12. Wascher DC, Dvirnak PC, DeCoster TA. Knee dislocation: initial assessment and implications for treatment. J Orthop Trauma 1997;11:525-9.

13. Kennedy JC. Complete Dislocation Of The Knee Joint. J Bone Joint Surg Am 1963;45:889-904.

14. Kuhn MA, Ross G. Acute elbow dislocations. Orthop Clin North Am 2008;39:155-61.

15. Mehta JA, Bain Gl. Elbow dislocations in adults and children. Clin Sports Med 2004;23:609-27. 